\title{
Ocho AÑos de Trabajo
}

Este número ocho de la Revista Palobra es la culminación de una iniciativa de trabajo grupal, persistente y progresiva que, como lo han sido los números anteriores, es expresión tangible de la atenta y responsable vinculación que la Facultad de Ciencias Sociales y Educación mantiene con su entorno social, político y cultural. Han sido ocho años de trabajo sin interrupciones que ya han convertido a esta publicación en uno de los productos emblemáticos, no sólo de nuestra Unidad académica sino de la Universidad de Cartagena misma.

En esta edición se incluyen textos de diversa índole académica y editorial, tales como artículos productos de investigación, revisiones y discusiones propias de estados del arte, ensayos, documentos de trabajo, y otros, que discurren en temáticas abiertas y diversas, aunadas por el común interés de aportar a la comprensión de fenómenos estructurales o coyunturas particulares del ámbito local cartagenero, del entorno regional y nacional así como del más amplio latinoamericano.

En El Espacio Público en Cartagena de Indias, Resistencias Cotidianas, de Carmen Cabrales y Marcelo Cáceres, se plantea que el terreno de la confrontación por el espacio público en Cartagena es un fenómeno que, a pesar de su intensidad e implicaciones, se ha convertido en asunto de tratamiento público, tan sólo para los observadores atentos, pero no así para las autoridades encargadas de regular los usos y actividades del mismo ni para el grueso de la población que la habita. Según los autores de esta página de opinión, pareciera existir un profundo conflicto entre el significado de los espacios urbanos, la función colectiva que éstos tienen que cumplir y los usos que por diferentes necesidades efectivamente se les da. Muestran cómo el conflicto por el espacio público hace ya parte de la realidad de esta ciudad y consideran que las condiciones que prevalecen en ella harán que permanezca y se agrave si no median procesos constructivos de apropiación.

En La Lectura, la Escritura, el Pensar: La Formación. Condiciones para Con-versar Alrededor del Conocimiento y la Investigación, Luis Eduardo Pérez propone la conveniencia de asumir y explicitar los procesos educativos en los términos de una metáfora que los perfile mejor como trayecto que como mero proyecto, más como un andar permanente del sujeto que como un inmóvil y mero planeamiento académico. Se considera que la formación en su sentido más radical debe sustentarse y confluir en procesos que transformen a los sujetos cognoscentes así como los contextos que pretenden ser dilucidados y tocados 
por sus dinámicas.

El profesor de la Universidad Católica de Chile, Leonardo Oneto, colabora con Palobra en este número con un texto que se propone a manera de reflexión sobre los fundamentos de la acción profesional del Trabajo Social, De Las Representaciones Discursivas al Orden del Discurso: Una Perspectiva Discursiva de la Intervención del Trabajo Social. Este artículo se convierte en oportunidad de puntualizar los elementos de un modo de entender la intervención del trabajador social, que asumiéndola como construcción social, se auxilia con una comprensión que incorpora un conjunto complejo de variables intervinientes en la relación entre los procesos materiales y simbólicos que la constituyen. Abordaje que remite a la aproximación arqueológica de Foucault y a la pragmática discursiva contemporánea en su versión crítica, explicitando las dimensiones éticas y políticas del ejercicio profesional.

Gloria Bonilla, en su contribución, La Lucha de las Mujeres en América Latina: Feminismo, Ciudadanía y Derechos, explora los diversos discursos generados acerca de las mujeres, del feminismo y del sufragismo en América Latina, en los años que se suceden desde los albores de las primeras reivindicaciones feministas hasta la época en que finalmente las organizaciones sufragistas conquistaron la igualdad de derechos políticos para las mujeres. Interesa destacar a la autora, principalmente, el pensamiento de las mismas mujeres, las primeras que rompieron la tradición y empezaron a hablar y escribir para el público femenino sobre ellas mismas, en la dirección de la conquista de su ciudadanía. El artículo se divide en dos partes: una primera da cuenta de la lucha de las mujeres en América latina y la segunda se centra en el caso de Colombia.

En el artículo, La Configuración de la Identidad Local en la Diversidad Cultural: El Caso de Caucasia, Alejandro Pimienta se propone aportar a la comprensión del significado de lo local, presentando la configuración de la identidad grupal en una localidad del Departamento de Antioquia, a partir de procesos históricos de colonización e identificación sociocultural heterogéneos, enmarcados en la diversidad, especialmente por la convergencia, muchas veces conflictiva, del ethos sociocultural paisa y costeño. La descripción de ese proceso es la segunda parte del artículo. En la primera parte se presenta una problematización teórica de algunos conceptos que permiten la comprensión y análisis del fenómeno de la configuración de la identidad local en la diversidad cultural, que para muchos es paradójico.

En Los estudios de Pobreza Urbana, su autora, Rina de León, muestra en forma sucinta la evolución de los estudios de pobreza urbana; retoma para ello la 
producción escritural de investigadores que han hecho aportes valiosos sobre la temática en diferentes épocas y espacios geográficos. La información se ha organizado en dos unidades de análisis: la producción escritural en los países desarrollados y en los países en desarrollo, indagación articulada según categorías concomitantes con las de pobreza en contextos del desarrollo, como las de exclusión social y de desigualdad.

El documento de trabajo de Carmenza Jiménez y Leidy Perneth Exigencias Metodológicas del Abordaje de la Realidad Social desde un Enfoque Cualitativo con Perspectiva de Género: Una Experiencia en Construcción... da cuenta de las posturas teóricas asumidas y las rutas metodológicas emprendidas en la investigación Paternidad innovadora en Cartagena de Indias. Un análisis relacional entre el yo interpretado y la generación anterior, investigación que propone el género como perspectiva de análisis. Este estudio, del cual se desprenden las reflexiones metodológicas y teóricas de la presente colaboración, intenta comprender qué pasa y qué pasó en la vida de algunos padres para que hoy presenten quiebres y transiciones en el ejercicio de la paternidad y en sus identidades de género (entendidas como construcciones socioculturales), a partir de lo que narran de sí mismos en sus relatos vitales.

El documento de trabajo, Estableciendo Rastros para la Constitución de una Persona Activa de Derechos: El Cuerpo de la Violencia en la Historia de los Montes de María, de Orlando Durango y Mabel Valencia, rastrea en estos últimos años, el rostro de la violencia en la región de los Montes de María, en el Departamento de Bolívar. Explicitan y reflexionan en este documento sobre la experiencia, compartida por investigadores y actores sociales de algunos municipios bolivarenses de la región, de rescatar la invaluable historia de la apropiación material, simbólica y afectiva de un territorio y de unos imaginarios que luchan por dejar de ser los de la fuerza y de la intimidación para constituirse en condición de posibilidad y resultante de la constitución de un espacio, unas relaciones y una cultura alumbradas por la tolerancia, la confianza y, sobre todo, por la circulación de la palabra.

Por su parte, Fredi Goyeneche, con su Aproximación Interpretativa a Determinantes de la Violencia Homicida en Cartagena de Indias durante 2006, aporta algunas reflexiones significativas sobre el comportamiento anual de las muertes por homicidios durante 2006 en la ciudad. Este documento trabaja con las cifras condensadas y consolidadas del Informe de Muertes por Causa Externa (MCE), 2006, que incluyen además de los homicidios, las Muertes no Intencionales (MNI), las Muertes en Accidentes de Tránsito (MAT) y los Suicidios. Con las reflexiones interpretativas producto del seguimiento cuantitativo de estas cuatro variables se adentra el autor en la construcción de algunas explicaciones de carácter 
teórico y académico que propone para la mejor comprensión de algunas de las más complejas dinámicas urbanas de una ciudad atravesada por transformaciones radicales, fuera de toda previsión y manejo algunas de ellas, en todos los órdenes de su realidad.

Ruby Esther León, en Trabajo Social Intercultural: Algunas Reflexiones a Propósito de la Intervención con una Comunidad Indígena del Trapecio Amazónico Colombiano, elabora un análisis sobre la manera cómo se realizó una intervención profesional en la comunidad indígena de Mocagua, a propósito del impulso al Plan Integral de Vida (PIV). Propone la autora tener en consideración tres dimensiones que encuadran dichas reflexiones en el antes, el durante y el después de la intervención. En primer lugar, se aborda la dimensión conceptual de la intervención intercultural que contiene a su vez categorías discursivas y políticas que justifican la acción profesional. En segundo lugar, se examina la dimensión metodológica que da cuenta de la práctica profesional en sí misma, la cual trasciende la mera técnica pues desde allí se involucra no solamente a los sujetos con los cuales se construye el entramado interventivo sino también el sujeto profesional. Por último, se plantea una mirada a la dimensión ética del impulso de un Plan Integral de Vida en una comunidad indígena, pues desde allí considera posible cuestionar propuestas conceptuales y metodológicas homogenizantes sobre la manera de ver lo indígena. Para la autora, el programa "Plan Integral de Vida", es también un excelente escenario para estudiar la forma cómo se concibe la inclusión de la diversidad étnica a la Nación.

Finalmente, y de cara al ya activado proyecto de publicación de nuestro próximo número en el año 2008, el Comité Editorial de Palobra renueva la invitación a todos los investigadores, académicos en general, y estudiosos de las temáticas de lo social, a que se vinculen a un proyecto que más que meramente editorial, se constituye en una propuesta de construcción responsable, razonada y solidaria de futuro.

El Editor 